\title{
La producción audiovisual como medio de difusión de la música nacional
}

\section{Audiovisual production as a means of disseminating national music}

Carlos Eduardo Zambrano Tacuri

Universidad Politécnica Salesiana, Ecuador

Marlene Mosquera

Universidad Politécnica Salesiana, Ecuador

Autor para correspondencia: czambranotacuri@outlook.com, mmosquerag@ups.edu.ec

Fecha de recepción: 27 de Julio 2017 - Fecha de aceptación: 15 de Enero de 2018

Resumen: La producción audiovisual en el Ecuador está creciendo como un medio de difusión de artistas locales. Pero la difusión de la música nacional (albazo, pasillo, yaravi, pasacalle, entre otros) en la actualidad presenta graves dificultades debido a la masificación y globalización en el internet de empresas que a través del marketing logran posicionar a sus clientes; otro problema es la poca actualización del contenido audiovisual para generar expectativa. Esta investigación busca analizar el impacto de la producción audiovisual en la difusión de la música nacional en la ciudad de Guayaquil, a través de los criterios de los actores sociales involucrados en la temática, como artistas, productores, difusores y ciudadanía. Determinando la influencia que generan las producciones audiovisuales en la sociedad guayaquileña. Así como identificar referentes artísticos de la escena musical nacional con el afán de comprobar si tienen una difusión efectiva que aporta a la cultura nacional desde la promoción y la masificación de sus temas mediante videoclips. Las producciones audiovisuales sirven como medio de difusión para la música nacional, pero no logran una repercusión destacada en el país, por lo cual es importante generar nuevos y mejores espacios que colaboren a la difusión de estas expresiones artísticas.

Palabras clave: producción audiovisual; música nacional; medios de comunicación; cultura; videoclip

Abstract: Audiovisual production in Ecuador is rising up growing as a medium of dissemination for local artists. However, the diffusion of the national music (albazo, pasillo, yaravi, pasacalle, etc) presents serious difficulties because the massification and globalization through the internet of companies that through the marketing manage to position their clients, another problem is the short update of the audiovisual content to generate expectation. This research seeks to analyze the audiovisual production impact on the diffusion of national music at Guayaquil city, through the criteria of the social actors involved in the theme, such as artists, producers, diffusers and citizenship. Determinate the influence generated by audiovisual productions in Guayaquil society. As well as identifying artistic references of the national music scene in order to check if they have an effective diffusion that contributes to the national culture from the promotion and the massification of their themes through video clips. Audiovisual productions serve as a medium for national music, but they do not achieve a significant impact in the country, so it is important to generate new and better spaces that contribute to the dissemination of these artistic expressions. Key words: audiovisual production; traditional music; media; culture; video clip 


\section{Introducción}

En Ecuador el apogeo de la música nacional se da a mediados del siglo XX donde los artistas locales demostraban su talento a través de programas radiales transmitidos en vivo y la congregación que generaban los mismos en sus recitales en las distintas plazas o centros culturales del país (Godoy, 2012). La sociedad ecuatoriana pasó su época dorada en esta etapa, allí varios artistas fueron los impulsadores de la música nacional como Julio Jaramillo, Dúo Benítez-Valencia, Hermanos Miño-Naranjo y otros cantantes insignia de la nación, quienes con sus composiciones impactaban en la comunidad gracias a la difusión provocada por la radio, ya sea por presentaciones en vivo o entrevistas.

En la región Costa, se evidencia mucho más la cercanía de la música contemporánea como el rock, el pop, la trova, el punk, urbano y demás experimentaciones artísticas, específicamente en la ciudad de Guayaquil existen un sin número de bandas o solistas que tienen propuestas alternativas y diversas frente a las existentes en el mundo comercial y globalizado de la actualidad, es decir, sin desmerecer al resto de ciudades, conlleva en sí fusiones musicales exquisitas con pinceladas de obras clásicas recogidas y adaptadas a la actualidad.

Entre ellos Luis Rueda, Héctor Napolitano, Ricardo Pita, Danilo Parra, Juan Fernando Velasco, Jorge Luis del Hierro, Mirella Cesa, entre otras grandes personalidades que han logrado forjar sus obras a través de la difusión e independencia musical en esta ciudad, siendo la catapulta ideal para llegar a impactar en el país de manera influyente y muchos de ellos avanzan su camino hacia la internacionalización.

La difusión de la música nacional en la actualidad presenta graves dificultades debido a la masificación y globalización del internet, las empresas dedicadas a este tipo de actividades musicales o marketing han acaparado el sector haciendo convenios con las páginas web más visitadas, volcando la oferta o demanda musical hacia los artistas de sus empresas, así como los más populares. La poca actualización de contenido audiovisual genera que la expectativa por avizorar alguna novedad no aparezca con facilidad en el usuario consumidor de música nacional.

El propósito de la investigación es analizar el impacto de la producción audiovisual en la difusión de la música nacional en la ciudad de Guayaquil, a través de los criterios de los actores sociales involucrados en la temática, como artistas, productores, difusores y ciudadanía en Guayaquil.

Determinar la influencia que generan las producciones audiovisuales en la sociedad guayaquileña y si esta se siente identificada con las propuestas musicales actuales. Así como identificar referentes artísticos de la escena musical nacional con el afán de comprobar si tienen una difusión efectiva que aporta a la cultura nacional desde la promoción y la masificación de sus temas mediante videoclips.

Mónaco (2015) define a la producción audiovisual como una serie de pasos a cumplir con la finalidad de transformar una idea en una cuestión que inmiscuya al arte visual y sonoro, además complementa que es: "un proceso de organización que permite convertir una idea en un producto terminado, exhibido y comercializado". (p. 15) 
Varios países latinoamericanos como Ecuador, Perú, Argentina y demás naciones han integrado entre sus temas musicales elementos de toda índole, lo cual confirma la ampliación del panorama sonoro entre territorios. Valdivieso \& Riofrío (2010) consideran que la expansión de la temática musical en cuanto a la exploración de sonidos ha colaborado a que la producción musical también se dé en formas mejor exploradas, aduce que:

En los últimos tiempos, la música responde a un mundo cada vez más globalizado con fuertes influencias extranjeras, como el rock y el pop de origen inglés y norteamericano, el propio continente, como la música protesta latinoamericana y la música del Caribe como cumbia, salsa y merengue y actualmente el reggae y el reggaetón. Estos ritmos se han ido adaptando al idioma, clases sociales y realidad socio-económica nacional, para dar origen a nuevas propuestas, como la tecnocumbia que se da tanto en el Ecuador como en el Perú. Se vive una época de integración, en la que encontramos mezclas de rock con música nacional, música clásica interpretada con instrumentos andinos; música tropical y género protesta se unen en festivales. (p. 37)

Para que los procesos de la producción audiovisual y música se realicen efectivamente es necesario que el estado promueva políticas que colaboren al desarrollo y la difusión de estos elementos, caso contrario quedarán como trabajos sin exposición mediática.

Restrepo (2013) comenta que la cultura es vital para el desarrollo de la sociedad, tanto que el gobierno apoyado en políticas estatales debe promover todo tipo de manifestaciones afines que realcen el propio conocimiento del arte realizado en el país que los acoge, además el autor comenta que:

El derecho a la cultura significaría, dentro de esta óptica, el derecho de toda persona a tener acceso en condiciones de igualdad a este capital acumulado. El desarrollo cultural se resumiría en una multiplicación de libros, bibliotecas, periódicos, museos, cobertura televisiva, etc. Las políticas culturales apoyarían la posición del creador individual en la sociedad. (p. 53)

El Ecuador es parte de la región latinoamericana, de la cual se tiene muy poca difusión en la actualidad, en cuestiones musicales, ya que la presencia de este género en el arte sonoro no llega a trascender de una forma masiva como es el caso de los otros géneros más vinculados a lo comercial.

Existen publicaciones internacionales que no toman muy en cuenta este tipo de géneros, pues en muchas ocasiones se los suele considerar de antaño o poco lucrativos en su defecto.

"Si revisamos estas publicaciones, podremos constatar que solo alrededor de un $1 \%$ del total de sus páginas está dedicado a la música latinoamericana. Ese 1\% normalmente incluye algunas referencias de la música indígena y folclórica de la región y particularmente del nacionalismo musical en América Latina, centrándose en tres figuras: Hector Villa-Lobos, Carlos Chávez y Alberto Ginastera - compositores favorecidos también en recuentos específicos sobre América Latina”. (Gonzáles, 2013, p. 26) 
Referente a esta cuestión, Giraldez (2010) considera a la identidad musical como algo perteneciente a todas las naciones del planeta, cada una tiene sus propias costumbres, cultura y tradiciones que varían de otras, lo cual solo significa que existe una diversidad total en el mundo, este vínculo entre música e identidad forma parte de las valorizaciones más destacadas para los estudiosos e investigadores sociales que se refieren en concreto al avance de sus distintos desarrollos. Además, aduce que:

“... la relación entre música e identidad ha sido una de las funciones más valoradas por parte de psicólogos y sociólogos. En concreto, para Frith (1981), las diferentes subculturas que se forman en torno a la música popular, como rockers, punks, heavies, etc., responden precisamente a ese uso de la música como emblema que comunica valores, actitudes y opiniones a los demás. Esta idea también subyace en diferentes estudios que relacionan las preferencias musicales y el comportamiento, indicando la relación entre algunos géneros musicales y la rebeldía e, incluso, la delincuencia". (p. 14)

La música para la región latinoamericana representa identidad, cultura y apego a los orígenes del ser humano que deben desembocarse, al menos en teoría, en la difusión concreta de este arte hacia todos los pobladores de la región, para aquello se necesitan los medios de comunicación de masas. "Debemos entender la producción musical como parte de un flujo de personas, ideas, mercancías, imágenes y sonidos que viajan alrededor del mundo, por efecto de nuevas tecnologías, diásporas migratorias y la mercantilización de la música. (Morejón, 2011, p.20)

La labor del videoclip en la música popular mundial es difundir la trascendencia de la música y llegar a desarrollar más fanáticos con el objetivo de recrear nuevas estrategias para que los medios de comunicación sean efectivos en su labor de difundir y llegar a la mayor audiencia posible.

“... es necesario comprender que la música popular es la música que, por efecto de la industria, los medios de comunicación, la tecnología y el flujo de personas se escucha y se produce. La inquietud es cómo entender por qué ciertos estilos musicales populares se escuchan en determinados niveles y contextos. De ahí que lo importante es ubicar los procesos que hacen posible que ciertos estilos musicales alcancen una escala global, al mismo tiempo que se les da significados particulares en los distintos contextos geográficos a los que llegan y en los que se producen”. (Morejón, 2011, p.26)

La intención de los medios de comunicación, llevada al plano de la práctica referente a la música es la de lograr que la cultura sonora de cada nación o territorio se vea representada en sus contenidos, no solo con temáticas extranjeras sino también abarcar los espacios de música nacional en todos sus géneros.

“... la escasez o casi ausencia de fondos y recursos económicos destinados a fomentar la producción nacional en ámbitos claves como el cine que puede ser el vehículo para que se discuta de cultura, de imaginarios y problemáticas sociales, y por otra parte, hay que recordar que en Ecuador no existe una ley de cinematografía; la ausencia de planificación estatal en el campo de la cultura se traduce además en la imposibilidad de concebir y viabilizar instancias o 
trayectos de formación capaces de garantizar y capitalizar las energías creativas de las nuevas generaciones, las que precisamente hablan y se expresan por medio del audiovisual u otra nuevas tecnologías". (Acosta y Falconí, 2005, p. 249)

Los artistas nacionales han encontrado cierto refugio en las redes sociales y el avance de la comunicación en internet lo cual ha llevado a que las promociones de sus nuevos lanzamientos las hagan por medio de estas plataformas de alcance global. Varios artistas locales han llegado a considerar este medio como un importante logro en la comunicación, pues logra un efectivo alcance e interacción con el público y posibilita que nuevas audiencias sepan de sus obras musicales y audiovisuales, abriendo el campo en un plano de corte mundial y de posibilidades bastante amplias.

\section{Metodología}

La presente investigación académica realiza la aplicación de metodologías cualitativas y cuantitativas. El enfoque mixto propone la utilización de ambas metodologías para que la investigación tenga una rigurosidad planteada en la aplicación de encuestas a la muestra finita obtenida de la población guayaquileña. Además, tendrá tratamientos relevantes con entrevistas a profundidad a un grupo involucrados en la temática de la música nacional con la finalidad de determinar el alcance de las producciones audiovisuales en la sociedad, así como su influencia y qué opiniones tiene la ciudadanía y los expertos al respecto.

La importancia de la aplicación de encuestas se enfoca en receptar las perspectivas de manera cuantitativa y generar así un espacio para el posterior análisis y crítica de los resultados obtenidos.

Según el Instituto Nacional de Estadísticas y Censos: INEC (2011) la ciudad de Guayaquil cuenta con 2'291.158 habitantes aproximadamente, categorizado como el espacio de territorio con mayor cantidad de población, lo que desembocaría en que este proyecto académico obtenga una connotada relevancia, pues el lugar que está siendo referencial para esta actividad tiene gran importancia dentro del panorama ecuatoriano, tanto poblacional como artístico e influyente.

Tabla 1: Ficha técnica de trabajo de campo (encuestas)

\begin{tabular}{ll}
\hline Población & $\mathbf{2 ’ 2 9 1 . 1 5 8}$ \\
\hline Alcance & Todas las parroquias de Guayaquil \\
Tipo de Encuesta & Personal autoadministrada \\
Método de Muestreo & Por cuotas por fijación proporcional \\
Tamaño muestral & 386 \\
Nivel de Confianza & $95 \%$ \\
Heterogeneidad & $50 \%$ \\
Margen de error & $5 \%$ \\
\hline \multicolumn{2}{c}{ Fuente: Carlos Zambrano Tacuri }
\end{tabular}


Dentro de la investigación se realizaron encuestas aplicadas por fijación proporcional de la población guayaquileña, abarcando las parroquias de dicha ciudad. El objetivo fue el cuantificar la opinión pública para su posterior análisis, lo cual representa un aporte significativo e importante para la presente investigación.

Tabla 2: Ficha técnica del método de muestreo por cuotas

\begin{tabular}{cccc}
\hline Parroquias & Población & Encuestas Aplicadas & Porcentaje De La Muestra \\
\hline Tarqui & 1050826 & 177 & $45,85 \%$ \\
Ximena & 546254 & 92 & $23,83 \%$ \\
Febres Cordero & 343836 & 58 & $15,03 \%$ \\
Letamendi & 95943 & 16 & $4,15 \%$ \\
Pascuales & 74932 & 13 & $3,37 \%$ \\
Chongon & 36726 & 6 & $1,55 \%$ \\
Urdaneta & 22680 & 4 & $1,04 \%$ \\
Garcia Moreno & 50028 & 8 & $2,07 \%$ \\
Sucre & 11952 & 2 & $0,52 \%$ \\
Periferia & 12467 & 2 & $0,52 \%$ \\
Ayacucho & 10706 & 2 & $0,52 \%$ \\
9 de Octubre & 5747 & 1 & $0,26 \%$ \\
Bolivar & 6758 & 1 & $0,26 \%$ \\
Olmedo & 6623 & 1 & $0,26 \%$ \\
Pedro Carbo & 4035 & 1 & $0,26 \%$ \\
Roca & 5545 & 1 & $0,26 \%$ \\
Rocafuerte & 6100 & 1 & $0,26 \%$ \\
TOTALES & 2291158 & 386 & $100,00 \%$ \\
\hline
\end{tabular}

Fuente: INEC (2011) y Carlos Zambrano Tacuri

Las entrevistas a profundidad tienen como objetivo captar impresiones o perspectivas de representantes de la producción audiovisual en conjunto con músicos o artistas guayaquileños relacionados a la propuesta de investigación del artículo académico y la difusión de sus obras musicales.

Tabla 3: Ficha técnica de los entrevistados

\begin{tabular}{cc}
\hline Entrevistado & Experiencia \\
\hline Dr. Pedro Álava & Músico y productor artístico \\
Productor Danny Abad & Productor Musical \\
Ing. Fausto Zambrano & Estudiante de la Escuela del Pasillo \\
Lcdo. John Mite & Docente y Comunicador Social \\
Lcdo. Patricio Palma & Docente de Educación Artística \\
Pilar Garay Luzuriaga & Estudiante de la Escuela del Pasillo \\
Lcdo. Jacinto Fajardo & Radiodifusor cultural \\
\hline \multicolumn{2}{c}{ Fuente: Carlos Zambrano Tacuri }
\end{tabular}

\section{Resultados (Encuestas)}




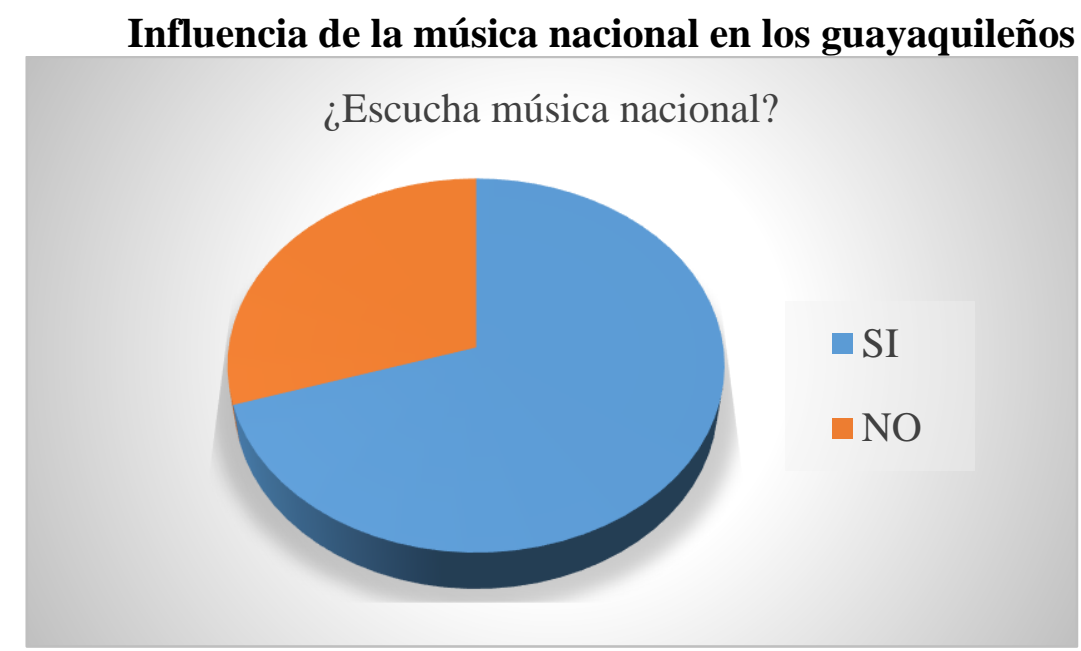

Figura 1. Fuente: Carlos Zambrano Tacuri

El 70\% (270 encuestados) contestó afirmativamente que escucha música producida en el Ecuador.

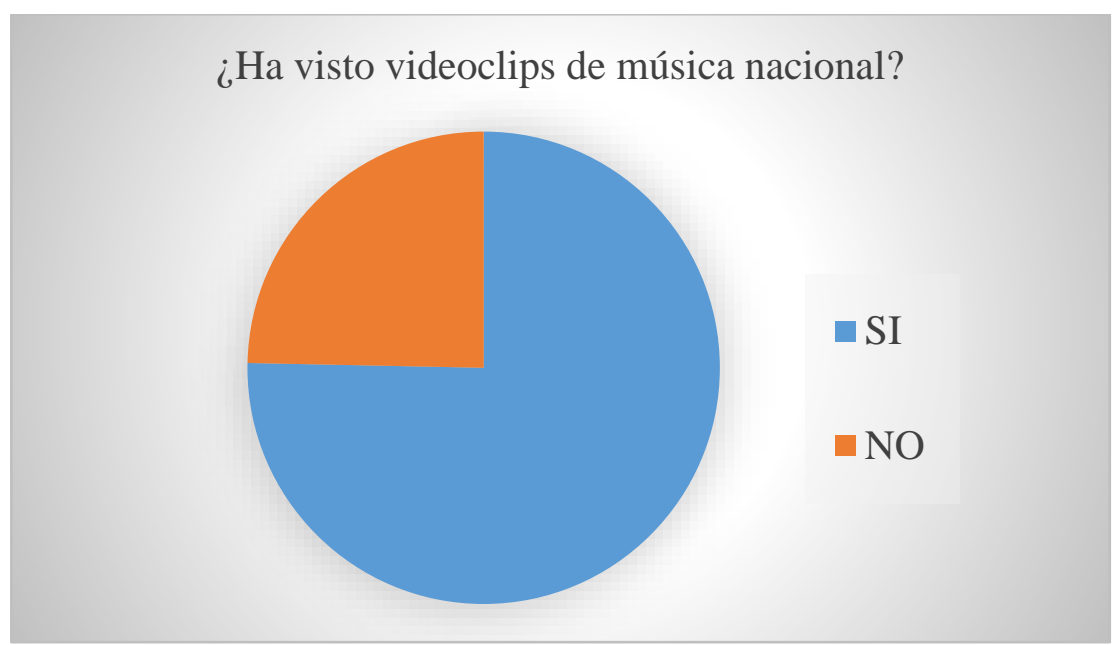

Figura 2. Fuente: Carlos Zambrano Tacuri

El 75\% (290 personas) de los encuestados respondió que ha visto videoclips de música nacional. 


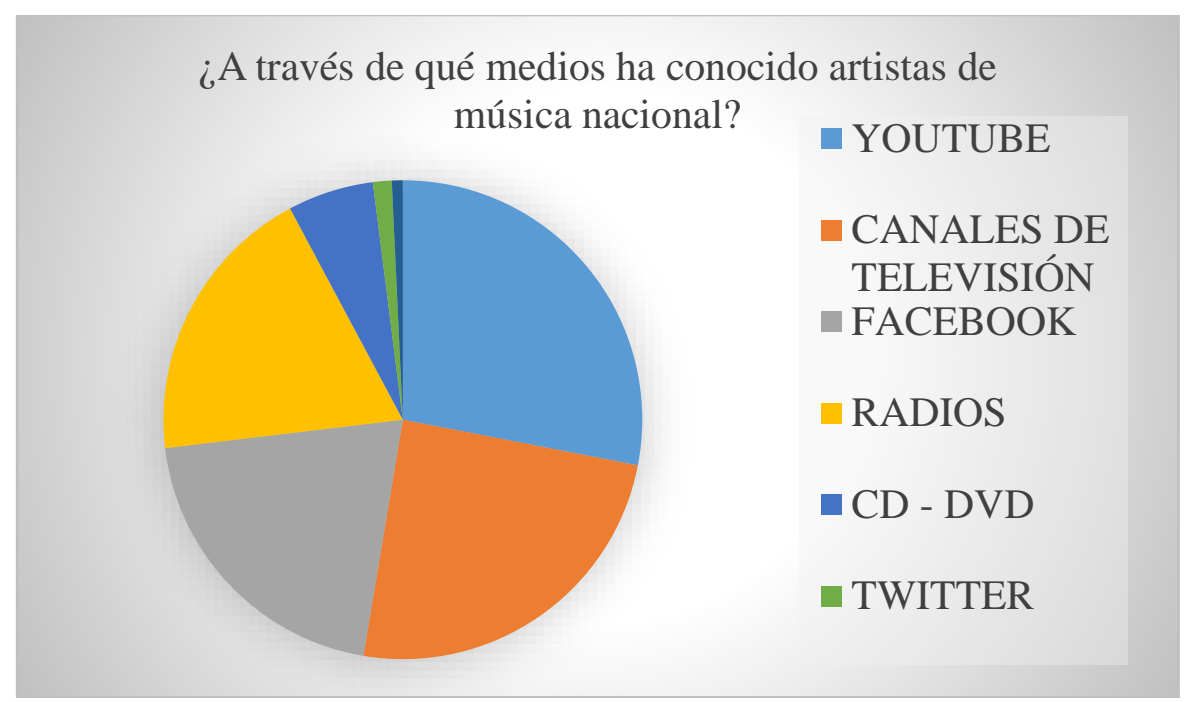

Figura 3. Fuente: Carlos Zambrano Tacuri

YouTube, televisión, Facebook y radios con 28\%, 25\%, 20\% y 19\% respectivamente son los medios por los que conocen de artista nacionales.

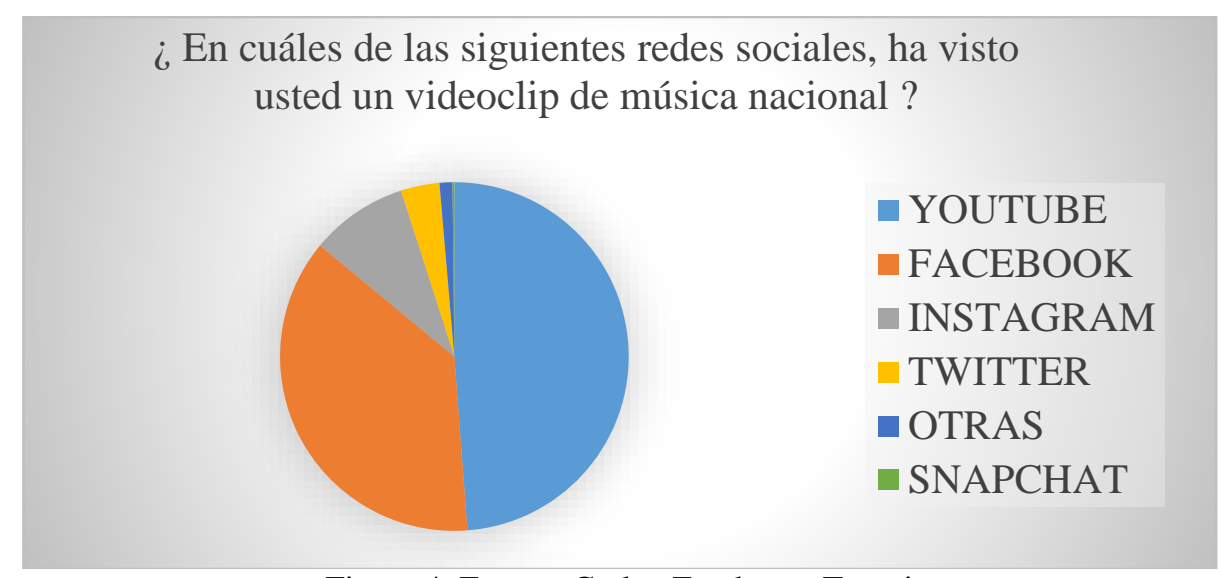

Figura 4. Fuente: Carlos Zambrano Tacuri

Los encuestados tienen a YouTube (49\%) y a Facebook (37\%) como redes sociales donde mayoritariamente visualizan los videoclips de música nacional.

\section{Referentes de los géneros musicales}

Sobre géneros musicales más escuchados son balada y pop ocupan los primeros lugares. No obstante, el pasillo se ubica con un $14 \%$ que son tres puntos debajo del rock, reggaetón y rap (17\%) que son música urbana. 
De los siguientes géneros: ¿Cuáles ha visto en producciones audiovisuales videoclips?

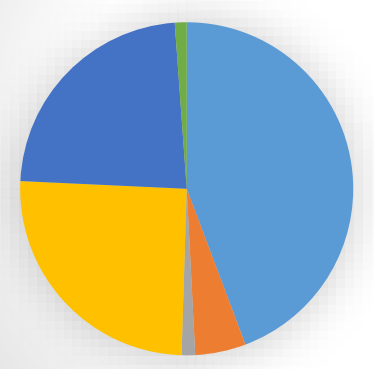

$$
\begin{aligned}
& \text { PASILLO } \\
& \text { BOMBA } \\
& \text { ALBAZO } \\
& \text { SAN JUANITO } \\
& \text { PASACALLE } \\
& \text { YARAVI }
\end{aligned}
$$

Figura 5. Fuente: Carlos Zambrano Tacuri

Sobre la observación de videoclips de géneros musicales nacional, el pasillo ocupa el $44 \%$, el san Juanito el $25 \%$, el pasacalle el $23 \%$, la bomba el $5 \%$, el albazo el $2 \%$ y el yaraví el $1 \%$.

\section{Referentes artísticos de la escena musical nacional}

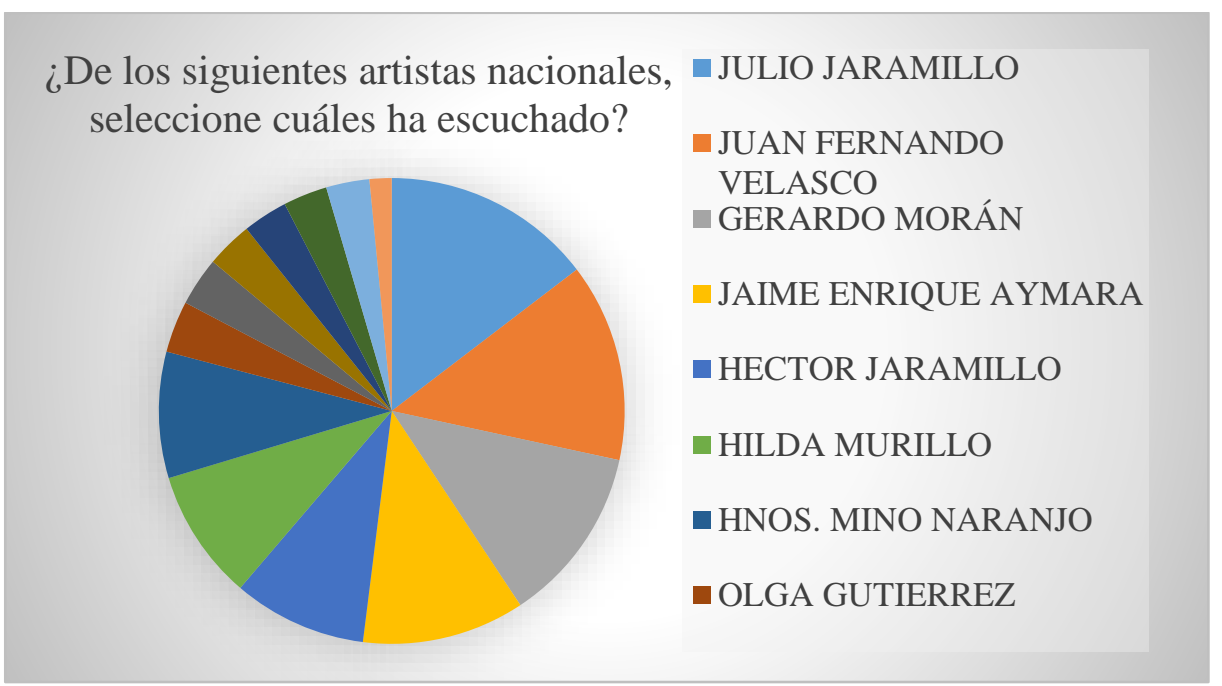

Figura 6. Fuente: Carlos Zambrano Tacuri

Los artistas nacionales más escuchados Julio Jaramillo ocupa el 15\%, Juan Fernando Velasco el 14\%, Gerardo Morán 12\%, Jaime Enrique Aymara 11\%, y el 9\% a los artistas Héctor Jaramillo, Hilda Murillo y Hnos. Miño Naranjo. 


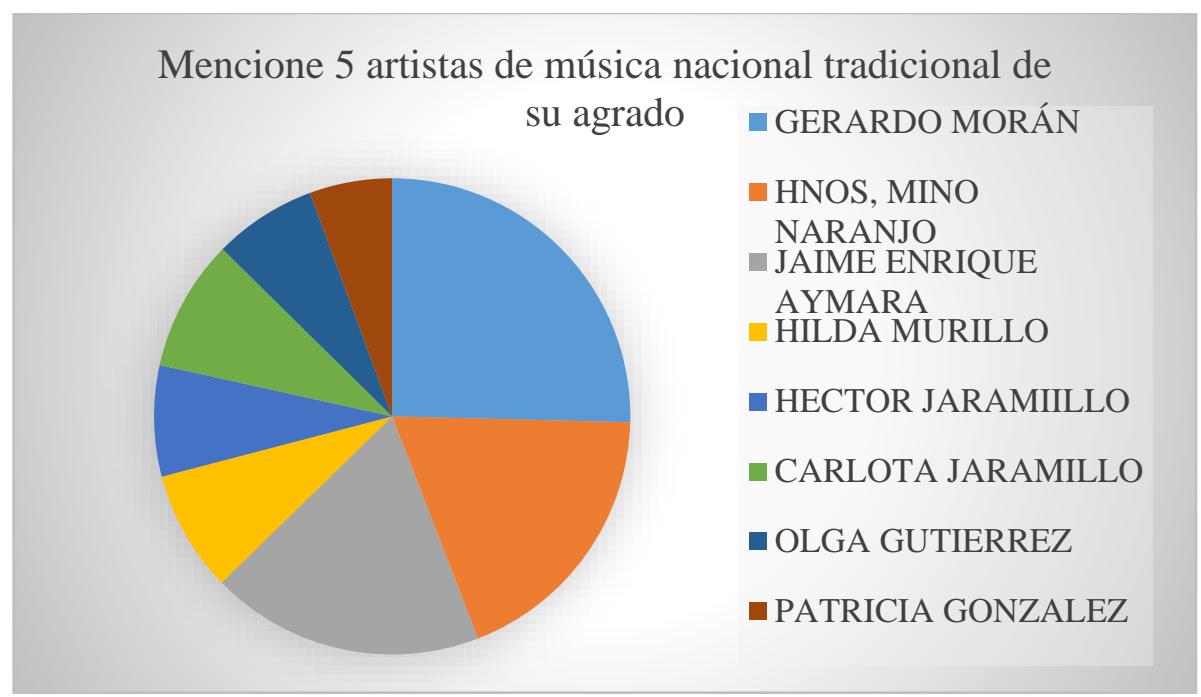

Figura 7. Fuente: Carlos Zambrano Tacuri

Se indaga sobre músicos tradicionales que gocen con el agrado de la opinión pública, Gerardo Morán ocupa el 25\%, Hnos. Miño Naranjo el 19\%, Jaime Enrique Aymara el 19\%, Hilda Murillo el 8\%, Héctor Jaramillo 7\%, Carlota Jaramillo 9\%, Olga Gutiérrez 7\% y Patricia González 6\%.

Los encuestados también mencionaron como artistas de música nacional a cantantes o grupos locales que incursionan en el género pop, entre ellos mencionaron mayoritariamente a los grupos musicales Verde 70 obtiene 19\%, Tranzas el 16\%, LEGO el 10\%. Los solistas como Maykel 9\%, Daniel Beta 8\%, Nikki Mackliff 8\%, Pamela Cortes y AU-D con el 6\% tuvieron menos menciones.

\section{Análisis de las entrevistas}

En el presente apartado se expone el criterio de los actores sociales involucrados en la temática, como artistas, productores y difusores. Dentro de la realización de entrevistas se pudo constatar, basado en opiniones y argumentos de los personajes involucrados, la importancia y necesidad de desarrollar la temática en cuanto al videoclip en conjunto con su potencial capacidad difusora de artistas y músicos en general.

Abad (2016), sonidista y productor musical, considera que la industria ecuatoriana en el arte sonoro está en constante crecimiento y por buen camino, dentro de su trabajo con artistas que interpretan géneros diferentes como pasillo y otros más diversamente contemporáneos destaca que en la actualidad el músico ecuatoriano busca plantearse como un profesional y se dedica a ellos mediante el estudio y la preparación adecuada en el país o en el extranjero.

Con respecto a las producciones audiovisuales de temas musicales o videoclips, menciona que tiene un desarrollo importante desde la autogestión y el autofinanciamiento, ya que, en la mayoría de los casos, no cuentan con los recursos necesarios para ejercer una difusión más profunda. 
Para Abad, (2016) las plataformas digitales vencen a los medios tradicionales y constituyen la direccionalidad específica en cuanto al establecimiento de una nueva forma de difusión de videos musicales y sobre todo de los temas que ellos interpretan.

Dentro de la rama de lo juvenil y académico, uno de los interventores en esta cuestión es el docente y licenciado en artes Palma, (2016) pues cree que la música nacional parece ser un espacio mucho mejor tratado en la actualidad que en anteriores épocas, aunque reconoce que falta mucho por hacer en cuanto a la materia de educación desde un enfoque musical.

El catedrático y director de agrupaciones de música popular ecuatoriana, considera que representar música nacional en un videoclip significa un desafío importante para el desarrollo de la identidad nacional y que se deben utilizar todos los recursos posibles para su eficaz difusión. Además, ve en las redes sociales un potente canal de respaldo, pues dentro de las tareas escolares que él envía se encuentran la búsqueda e investigación por parte de los estudiantes sobre temáticas y canciones que han marcado épocas dentro del pentagrama ecuatoriano, asegurando así una memoria colectiva en su estudiantado.

El videoclip según Alava, (2016) es la puerta abierta que deja un tema musical para su difusión en redes sociales, pues entendiendo las nuevas tecnologías de la información y la comunicación, plantea un vínculo más directo con la audiencia desde plataformas como YouTube y aplicaciones como Spotify o Itunes.

El músico y comunicador Mite, (2016) plantea que la situación actual en cuanto al desarrollo del videoclip como medio de difusión se encuentra en una etapa de producción, visualiza la problemática en el desarrollo de la difusión y la gestión para que más gente pueda llegar a conocer tal tema musical o tal producto audiovisual.

Zambrano (2017), ingeniero e integrante de la Escuela del Pasillo de Guayaquil considera que la música nacional es de vital importancia para que la sociedad ecuatoriana pueda continuar un proceso de autoconocimiento e identificación propia con sus tradiciones y sus diferentes manifestaciones expresivas.

Garay (2017), también estudiante de la Escuela del Pasillo, menciona que la difusión de la música nacional no se realiza correctamente por los medios de comunicación; también señala que varias producciones audiovisuales no son realizadas con una calidad debida, lo cual desacredita al artista que participa en dicha cuestión.

Fajardo (2017), radiodifusor del arte nacional aduce que para crear un referente en las generaciones y se puedan desarrollar un gusto y una cercanía con estas expresiones de la cultura nacional, los medios de comunicación son los llamados a difundir la música ecuatoriana.

\section{Conclusiones}

Basado en desarrollo y exposición de resultados es importante acotar que los músicos nacionales gozan de una mesurada aceptación por parte de la opinión pública, así como también tienen conocimiento acerca de las producciones audiovisuales realizadas en el Ecuador. 
Entre los puntos a destacar acerca de los resultados de la presente investigación se encuentra el hecho de que la ciudadanía consultada conoce a los artistas nacionales que los medios de comunicación tradicionales ofrecen dentro de su programación.

Las producciones audiovisuales sirven como medio de difusión para la música nacional, pero no logran una repercusión destacada en el país, por lo cual es importante generar nuevos y mejores espacios que colaboren a la difusión de estas expresiones artísticas.

Las redes sociales sirven como una nueva plataforma que es acogida por los jóvenes y las generaciones adaptadas a la tecnología; lo cual podría ser un espacio de vital importancia para que las difusiones de las producciones audiovisuales nacionales logren destacarse y llegar a la mayor cantidad de público posible.

Es importante destacar los esfuerzos de la empresa privada, el gobierno nacional y grupos de artistas que generan espacios de difusión en diversas plataformas de todo tipo, aunque no es suficiente para llevar adelante la casi nula industria musical ecuatoriana, aunque es una tarea pendiente de la sociedad.

La producción nacional ecuatoriana tiene destellos y calidad comparada a audiovisuales extranjeros y renombrados, lo que aún no se logra concretar son dos cosas esencialmente: como primer punto la deuda pendiente principal es lograr una mejor difusión, integradora y diversa, por otro lado, la sociedad debe ser investigadora, curiosa, ávida de arte y que esta busque constantemente expresiones nuevas en el entorno en el cual se desarrolla.

Aquella deuda se logrará menguar con la colaboración de todos los sectores que integran esta coyuntura, para mejorar en estas cuestiones es necesario y de vital importancia que el gobierno de turno siga incentivando espacios y políticas favorables a la propiedad intelectual de los creadores de audiovisuales; así como también compositores, músicos y artistas en general.

Por otro lado, el rol de los medios de comunicación social es fundamental, ya que las masas a las cuales se dirigen consumen lo que estos les ofrecen y es importante que las manifestaciones se muestren en diversidad y que el ecuatoriano común pueda sentirse identificado, es decir abrir oportunidades a que las producciones nacionales puedan ganar terreno mediante franjas musicales o programas dedicados exclusivamente a estos asuntos.

Finalmente, el papel más importante y destacado dentro de toda esta contienda es el que juegan los actores sociales, la comunidad y toda la población ecuatoriana, pues si no existe una iniciativa personal o el deseo de querer hallar nuevas expresiones artísticas con las cuales puedan sentirse identificados, difícilmente se podrá sobre llevar una supervivencia de la música nacional y sus producciones audiovisuales como medios de difusión, si cada ciudadano busca por su propia cuenta artistas locales, seguramente se llevará gratas sorpresas y pueda ser el primer paso para el desarrollo del arte, la difusión y consagración de la música ecuatoriana.

\section{Bibliografía}


Acosta, A., \& Falconí, F. (2005). TLC: Más que un tratado de libre comercio. Quito, Ecuador: FLACSO. Obtenido de http://bit.ly/2rtOgLG

Frith, S. (1981). Sound effects; youth, leisure, and the politics of rock'n'roll. Sound effects; youth, leisure, and the politics of rock'n'roll.

Giráldez, A. (2011). Música: Complementos de formación disciplinar. Barcelona, España. Obtenido de http://bit.ly/2rfcNUg

Godoy, M. (2012). Historia de la Música del Ecuador. Quito, Pichincha, Ecuador. Obtenido de http://bit.ly/2rfBpMz

González, J. (2011). Pensar la música desde América Latina. Chile. Obtenido de http://bit.ly/2qKbhG7

Instituto Nacional de Estadísticas y Censos. (2010). Resultados del Censo 2010. Ecuador: INEC. Obtenido de http://bit.ly/1riLcfE

Mónaco, A. (2014). El ABC de la producción audiovisual. Ediciones CICCUS. Obtenido de http://bit.ly/2qK3urK

Viteri Morejón, J. P. (2011). Música y globalización: hardcore y metal en el Quito del siglo XXI (Master's thesis, Quito: Flacso sede Ecuador).

Restrepo, R. (2011). El derecho al arte en Ecuador. Ecuador: Instituto de Altos Estudios Nacionales. Obtenido de http://bit.ly/2rubMrE

Valdivieso \& Riofrío (2010). Guía Samana para Viajeros: Ecuador y sus Islas Galápagos. Obtenido de http://bit.ly/2rfpfmZ

Viteri, J. (2014). Hardcore y metal en el Quito del Siglo XXI. Quito, Ecuador: FLACSO - ABYA YALA. Obtenido de http://bit.ly/2qK718r

Abad, D. (09 de 08 de 2016). Productor Musical. (C. Zambrano, Entrevistador)

Alava, P. (10 de 08 de 2016). Doctor, Músico y Productor. (C. Zambrano, Entrevistador)

Fajardo, J. (04 de 05 de 2017). Radiodifusor. (C. Zambrano, Entrevistador)

Garay, P. (12 de 04 de 2017). Estudiante Escuela del Pasillo. (C. Zambrano, Entrevistador)

Mite, J. (15 de 09 de 2016). Docente y Comunicador Social. (C. Zambrano, Entrevistador)

Palma, P. (08 de 08 de 2016). Educador Artístico. (C. Zambrano, Entrevistador)

Zambrano, F. (20 de 04 de 2017). Ingeniero y Estudiante Escuela del Pasillo. (C. Zambrano, Entrevistador) 